\title{
An evaluation of the effectiveness of online clinical quandaries in increasing trainee clinical psychology knowledge
}

\section{Karen McKenzie ${ }^{1}$, Clara O'Shea ${ }^{2}$, Paula Megson ${ }^{3,}$ Hamish Macleod ${ }^{4}, \&$ Michael Begg ${ }^{5}$}

Summary: Game informed learning principles are increasingly being applied to both the wider educational context and specifically to allow the learner to role play a profession in a safe context prior to entering real practice. This questionnaire based study aimed to examine the impact of an online clinical quandary on the knowledge of trainee clinical psychologists in relation to challenging behaviour in people with a learning disability. Trainee knowledge in relation to key concepts required for successful assessment, intervention and evaluation of challenging behaviour was measured before and after using the clinical quandary, prior to any formal clinical psychology training $(n=62)$. Trainee views on the use of the clinical quandary were also gathered. A significant increase in scores was found after using the clinical quandary, for the following factors: dealing with the initial referral; recording and overall total scores. Trainees evaluated the quandary as interesting, challenging, stimulating and helpful as a study aid. The results suggest that online clinical quandaries may offer a useful learning tool for increasing trainee knowledge and allowing them to rehearse skills in an environment where mistakes do not impact on patients..

Keywords: online; clinical; quandary; training

1. Consultant Clinical Psychologist/Senior Lecturer, University of Edinburgh, Medical school. 2. Research Associate, University of Edinburgh, School of Education. 3. Psychology Associate, Andrew Lang Unit. NHS Borders. 4. Senior Lecturer, , University of Edinburgh, School of Education. 5. eLearning Manager, University of Edinburgh, College of Medicine and Veterinary Medicine

Address for Correspondence: Dr Karen McKenzie, University of Edinburgh, Medical school, Teviot place, Edinburgh, EH8 9AG.

kmckenzi@staffmail.ed.ac.uk.

7 Journal of Practice Teaching \& Learning 8(2) 2008, pp.7-24. DOI: 10.1921/81130. @ wE-b 


\section{Introduction}

\section{Game based learning}

Clinical psychologists, like many professions working in health and social care settings, undergo intensive training to ensure that they become competent and confident practitioners (BPS, 2001). There is, however, little research investigating the specific processes by which psychologists acquire their expertise or which educational approaches best facilitate it. The application of games to an educational context is increasingly being used both in the wider educational context (Sandford et al., 2006) and specifically to allow the learner to role play a profession in a safe context prior to entering real practice (Maharg, 2006; Begg et al., 2007). These developments offer the opportunity to evaluate the impact of a specific form of learning on the acquisition of expertise in trainee clinical psychologists.

It is argued that game based learning activities work because they facilitate the process whereby the individual undergoes an identity shift. Gee (2003) argues that computer games offer a means of entering a virtual 'community of practice' (Lave \& Wenger, 1991) and of rehearsing a different identity. The learner has a real world identity, which reflects their current status, capabilities etc; a virtual identity which is what they aspire to become, in this case a qualified clinical psychologist, and a projective identity which acts as a bridge between the two by allowing the individual to perceive that they can take on the virtual identity as a real world identity. A game based activity helps the individual increasingly move towards his or her desired identity in an active process in which the individual practices skills in a safe environment, makes links with their real world selves and is rewarded for effort and success (Gee, 2003).

Schaffer (2005) notes that game based learning activities can be developed for any given profession by identifying the core elements of its body of knowledge, culture and practices or 'epistemic frame' and using these to create an 'epistemic game'. 'Game informed learning' (Begg, 2008; Begg et al., 2005) proposes a model for developing learning activities that harnesses aspects of games that suggest good learning opportunities; consequential character roles, goals, immediate feedback, etc, without making the problematic and costly leap towards authoring something explicitly identified as a game. Game informed learning has made an effective impact within healthcare education (Begg et al., 2007) especially in the area of case based scenarios involving virtual patients (Begg et al., 2006).

8 Journal of Practice Teaching \& Learning 8(2) 2008, pp.7-24. DOI: 10.1921/81130. @ w\&-b 


\section{Developing a relevant game informed activity: Challenging behaviour and learning disability services}

The research outlined above suggests that a well-designed game informed activity, could offer an effective educational tool for any individual undergoing a professional training. In the present study, an online game informed learning activity was developed for trainee clinical psychologists, however, the same principles can be applied to any professional training. The epistemic frame from which the activity was developed was challenging behaviour in learning disability services because it is one of the most common reasons for referral to clinical psychology learning disability services (McKenzie et al., 2000), and therefore clinical psychologists are expected to have expertise in this area.

In order to design an activity in relation to challenging behaviour which was 'thickly authentic' (Shaffer, 2005) it was necessary to firstly identify the key formal and informal aspects of the practices of the clinical psychologist in relation to managing challenging behaviour. Ball et al. (2004), provide an evidence-based summary of the key factors in relation to successful assessment and intervention in cases of challenging behaviour. These include pre-assessment or mediator analysis, assessment, functional analysis and formulation, intervention, evaluation and feedback. These key elements were then incorporated into an online 'challenging behaviour' clinical quandary, using software called 'Quandary action mazes' (http://www. halfbakedsoftware.com/quandary.php). This software provides a basic structure which can be used to develop a scenario about which the learner must make a series of decisions. Each decision has consequences which leads the player on to a further scenario and decision. The game ends when the player makes a series of successful decisions and resolves the challenging behaviour clinical case.

\section{Mode of representation: Immersion and identity}

A key principle in good game design is mode of representation (de Freitas and Oliver, 2006). This refers to extent to which the learning activity resonates with and reflects the real life situation upon which it is based. For learning to take place, the game must initially seem relevant to and engage the player. Researchers have identified a number of factors that can help with this engagement, including: control,

9 Journal of Practice Teaching \& Learning 8(2) 2008, pp.7-24. DOI: 10.1921/81130. (C wEb 
challenge, curiosity and fantasy (Malone, 1980; 1982). Fantasy, in particular, has been shown to help the player to take on a 'character role' in the game (Begg et al., 2007) and to develop a projective identity (Gee, 2003). This fantasy can be facilitated through the use of role-play and metaphor (de Freitas, 2006) and if the player has some control over what the character does within the activity (Francis, 2006).

To promote this element of fantasy, the 'challenging behaviour' quandary begins by immediately placing the player in role, in this case, explicitly identifying him/her as a qualified clinical psychologist. In addition, the player is presented with details of a person who has been referred for challenging behaviour. These referral details are based on a composite of a number of real clinical cases, presenting a sense of 'authentic professionalism' (Gee, 2005) and introducing the player to the world of the clinical psychologist. The referral details and assigned role also present a 'back story' (Begg et al., 2005) which illustrate the rules of the game in terms of the values the player must adopt in role and the constraints this role places on them. A good game based learning activity demands that the player act as an authentic professional in order to 'win' the game (Gee, 2005).

This process can be further enhanced by providing opportunities within the learning activity for the player to access the tools of the trade of the professional. This includes links to additional information, assessment tools and definitions of key concepts, all of which may serve to heighten the immersion of the player in the practices, tools and value system that make up the domain of 'clinical psychologist'. The deeper the immersion in the domain, the more likely it is that knowledge associated with it will be learned (Shaffer, 2004). If these resources are provided 'just in time' (Gee, 2003) i.e. where and when the player requires it to progress, the learning is further situating within the context to which the learning will ultimately be applied.

\section{Mode of representation: Situated learning and challenge}

For game based or game informed learning activities to promote effective learning, they must also be embedded in the practice to which they relate and allow the player to generalise their learning from one context to another, by offering opportunities to pick up patterns that occur in real life, rather than just promoting abstract, general principles

10 Journal of Practice Teaching \& Learning 8(2) 2008, pp.7-24. DOI: 10.1921/81130. (๐ w\&b 
(de Freitas, 2006; Gee, 2003). The 'challenging behaviour' quandary, therefore, had to offer situated learning which was based on real clinical scenarios and psychological models which would be applied in real clinical practice (Ball et al., 2004). Likewise, the choices available within the quandary needed to reflect the range available in life, both good and bad. Gee (2003) notes that this 'transfer principle' i.e. where the strategies the player learns in the game are directly transferable to clinical practice, is another element of effective game based learning.

A good game based learning activity must not, however, be too predictable (de Freitas, 2006; Gee, 2003). Individual clients can do irrational and unexpected things and the psychologist must be prepared for this. While the quandary provides immediate feedback to the player in terms of the consequences of his/her decision, research suggests that this feedback should not always be what the player expects. Building unexpected consequences into the quandary also helps to challenge the player's lay person models about the world and introduces aspects of the semiotic domain of the clinical psychologist (Gee, 2003). Collins and Evans (2007) argue that one means of learning the tacit rules of a profession is to inadvertently break the rule. This is made possible in the quandary because it offers a psychosocial moratorium (Gee, 2003) in which mistakes can be repeated and learnt from.

\section{Are games, game based and game informed activities effective learning tools?}

Despite the increase in the use of games for educational purposes and the growing emphasis on outcomes research in professional education (Carpenter, 2005), there have only been a limited number of studies evaluating their use (de Freitas, 2006). Research provides mixed results, with some studies showing that the learning objectives has been achieved through the use of games (Green \& Bavelier, 2003) while others indicate that, while learning has taken place, this has not always related to the desired learning outcome (Sandford, 2006). O'Neil et al. (2005) undertook a meta-analysis which examined the extent to which games achieved specified learning outcomes and concluded that they were largely not achieving these, indicating either a complexity of learning through games that was difficult to capture in a simple learning objective or that games simply failed to help the student learn.

11 Journal of Practice Teaching \& Learning 8(2) 2008, pp.7-24. DOI: 10.1921/81130. @ wE-b 
It has been argued that the failure of game based activities to consistently achieve the pre-stated learning objectives reflects the need to place the games into a more directly relevant learning context (Facer et al., 2004) and to match the activity more closely to the needs of the learner (Biggs, 1999). In addition, de Freitas (2006) argues that, as well as formal assessment of learner performance, there is a need to evaluate game informed learning activities in terms of learner evaluations, particularly as evaluations which focus only on specific learning outcomes may not capture the process of the learning experience.

\section{The study}

\section{Aims}

The present study, therefore, had two aims:

1. To examine whether the use of a clinical quandary relating to the management of challenging behaviour in people with a learning disability had a significant impact on clinical psychology trainee knowledge as would be applied in clinical practice.

2. To assess the challenging behaviour clinical quandary based on the trainee evaluations following its use.

The specific hypothesis was that there would be a statistically significant increase in trainee knowledge scores compared to baseline scores, following the use of the clinical quandary, in the absence of any other input.

\section{Ethical approval}

Ethical approval was obtained from the University ethics committee.

\section{Design}

The study used a quantitative, within participants design.

12 Journal of Practice Teaching \& Learning 8(2) 2008, pp.7-24. DOI: 10.1921/81130. (C) wEb 


\section{Participants}

There were 62 participants in the study, all of whom were first year trainee clinical psychologists. Fifty (81\%) were female and 12 (19\%) were male.

\section{Setting}

The participants all initially took part in the evaluation during an induction event which introduced them to the online component of the learning disability module on the D.Clin. Psychol. Programme. This took place in the computer laboratory during the first week the trainees were on the course, prior to them receiving any formal teaching.

\section{Materials}

\section{Clinical quandary}

The clinical quandary was designed using the free software described above, taking into account the challenging behaviour good practice guidelines (Ball et al., 2004) and principles for designing a good game informed learning activity as outlined in the introduction.

\section{Case scenario questionnaires}

Two challenging behaviour case scenario based questionnaires were designed to measure trainee knowledge about the basic factors required for successful intervention in relation to challenging behaviour. The first related to a female client who displayed aggression and the second to a male client who displayed behaviour which damaged property and disrupted services. Both case scenarios were based on a composite of real challenging behaviour referrals which had been received by the first author as part of her clinical practice. The case scenarios were matched in terms of the basic underlying information that they provided. For example, both related to a different example of challenging behaviour and in both scenarios the behaviour was being maintained by staff responses.

Each questionnaire contained 14 identical questions, which covered the following main factors, all of which had been identified in the professional good practice guidelines in relation to challenging behaviour (Ball et al., 2004): dealing with the initial referral, recording

13 Journal of Practice Teaching \& Learning 8(2) 2008, pp.7-24. DOI: 10.1921/81130. (C wE-b 
Karen McKenzie, Clara O'Shea, Paula Megson, Hamish Macleod, \& Michael Begg

the behaviour, functional analysis, intervention and evaluation.

Quandary evaluation questionnaire

This questionnaire asked the trainees to rate the quandary on a five point Likert scale in relation to the following aspects: interest, ease of use, challenge, control, helpfulness as a study aid and likelihood of using the quandary again. The trainees were also asked what the main challenges of the quandary were and what they had learnt from its use.

\section{Procedure}

All participants were given clinical case scenario 1 and the associated questionnaire which covered the factors outlined above. Following completion, they were given online access to the challenging behaviour clinical quandary. They were asked to work through this at their own pace and indicate when they were finished. At this point they were given the second clinical case scenario. The trainees were asked to mark both questionnaires with some symbol which would allow for the questionnaires to be matched. Finally they were asked to complete the clinical quandary evaluation questionnaire. All responses were anonymous.

\section{Scoring}

Case scenario questionnaires

Responses were scored according to absence or presence of key pieces of information. These were determined from professional good practice guidelines (Ball et al., 2004) and from published research by recognised experts in the field (e.g. Emerson et al., 2000). The 14 questions were combined to give 6 scores: dealing with the initial referral, recording, functional analysis, intervention, evaluation and an overall total score.

Quandary evaluation questionnaire

Likert scores were analysed to give mean scores and standard deviations. Responses to the open-ended questions were grouped into response categories and frequency counts calculated.

14 Journal of Practice Teaching \& Learning 8(2) 2008, pp.7-24. DOI: 10.1921/81130. @ w\&b 


\section{Statistical analysis}

\section{Power calculation}

A power calculation was carried out to determine the number of participants required for the study. Power was set at .80 according to convention set by Cohen (1992) and alpha level at 0.05. There had been no previous research specifically carried out in this area to allow an exact effect size to be calculated, however a previous study which had examined the impact of training on staff knowledge in relation to challenging behaviour (McKenzie et al., 2000) found a large effect size. Assuming power of .80, a large effect size would require approximately 11 participants for a related t-test and a medium effect size would require approximately 25 . The present study had 62 participants.

\section{Results}

\section{Hypothesis}

There will be a statistically significant increase in trainee knowledge scores following the use of the clinical quandary at the very beginning of training, in the absence of any other input.

Table 1 illustrates the mean and standard deviations of participant scores for the six factors at baseline and follow up, the $t$ values and significance levels for all factors scores and effect sizes for the statistically significant results.

A series of paired samples t-tests indicated that there was a statistically significant increase in scores between baseline and follow up after using the clinical quandary for the following factors: dealing with the initial referral; recording and overall total scores. There was no statistically significant increase in scores in relation to the following questions: functional analysis; intervention and evaluation.

15 Journal of Practice Teaching \& Learning 8(2) 2008, pp.7-24. DOI: 10.1921/81130. @ wEb 
Karen McKenzie, Clara O'Shea, Paula Megson, Hamish Macleod, \& Michael Begg

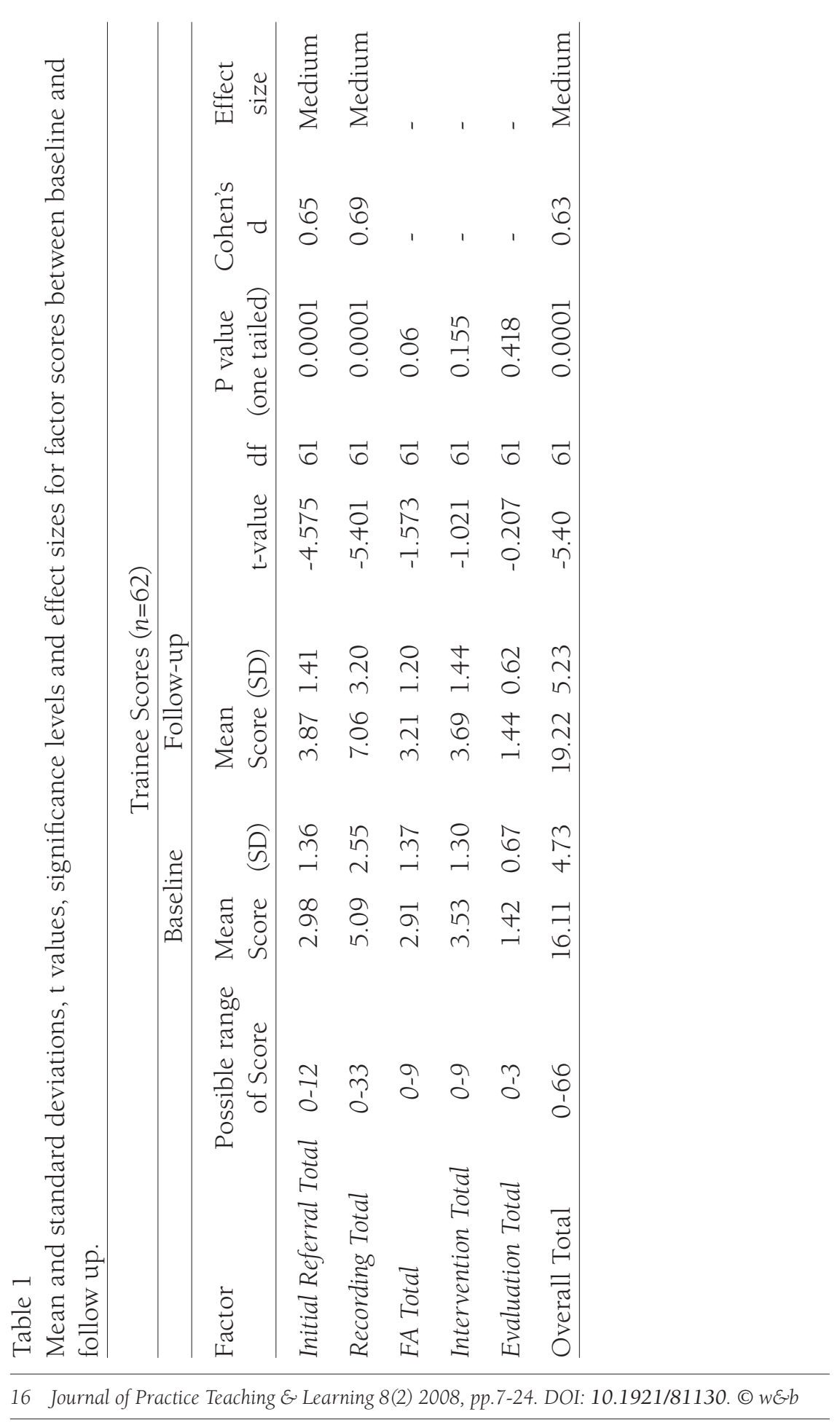


Table 2

Mean and standard deviations for trainee scores in relation to questions 1- 6 on the Quandary Evaluation Questionnaire

\begin{tabular}{lccl} 
Question & Mean & SD & Ratings \\
$\begin{array}{l}\text { How interesting } \\
\text { was the quandary? }\end{array}$ & 1.3 & 0.6 & $\begin{array}{l}\text { ( } 1=\text { very interesting, } \\
5=\text { very tedious })\end{array}$ \\
\hline $\begin{array}{l}\text { How easy did you find } \\
\text { the quandary to use? }\end{array}$ & 2.6 & 0.9 & $\begin{array}{l}\text { ( } 1=\text { very easy, } \\
5=\text { very difficult })\end{array}$ \\
$\begin{array}{l}\text { How stimulating was } \\
\text { the quandary? }\end{array}$ & & & \\
challenging) & 1.9 & 0.6 & $\begin{array}{l}(1=\text { very challenging, } \\
5=\text { not at all })\end{array}$ \\
\hline
\end{tabular}

How much control did you feel you had over the direction of the quandary? 2.30 .9 (1=complete control, How helpful was the quandary as a study aid? $1.3 \quad 0.7$ (1= very helpful,

How likely are you to $5=$ useless)

$\begin{array}{lll}\text { use the quandary again? } & 1.2 & 0.5\end{array}$ ( $1=$ definitely, $5=$ definitely not).

\section{Trainee evaluations of the challenging behaviour quandary}

Table 2 illustrates the mean and standard deviations for trainee scores in relation to questions 1- 6 on the Quandary Evaluation Questionnaire

Table 3(i) and 3(ii) illustrates the trainee responses to the question 'What were the main challenges of the quandary?' and 'What did you learn from the quandary?' 
Table 3(i)

Student responses to question. "What were the main challenges of the quandary?

\begin{tabular}{|l|l|l|l|}
\hline \multicolumn{1}{|c|}{ Category of response } & No. & $\%$ & \multicolumn{1}{c|}{ Example } \\
\hline $\begin{array}{l}\text { Having no or limited } \\
\text { experience and } \\
\text { knowledge of learning } \\
\text { disabilities }\end{array}$ & 20 & 38 & $\begin{array}{l}\text { 'Limited knowledge due to not much experience } \\
\text { in Learning Disabilities.' } \\
\text { 'Not having knowledge of LD, hard to answer } \\
\text { some of the questions.' }\end{array}$ \\
\hline $\begin{array}{l}\text { Deciding between } \\
\text { the different options } \\
\text { offered }\end{array}$ & 24 & 46 & $\begin{array}{l}\text { 'Number of possible options so often unsure } \\
\text { which one is best.' } \\
\text { 'Having more than one option that seemed } \\
\text { appropriate.' }\end{array}$ \\
\hline $\begin{array}{l}\text { Didn't find it } \\
\text { challenging }\end{array}$ & 4 & 8 & $\begin{array}{l}\text { 'I didn't find it especially challenging.' } \\
\text { 'I found no real challenges in the quandary, but } \\
\text { was left intrigued by where other paths would have } \\
\text { taken me.' }\end{array}$ \\
\hline $\begin{array}{l}\text { Technical/processing } \\
\text { aspects }\end{array}$ & 4 & 8 & $\begin{array}{l}\text { 'I wasn't sure about going back pages so I just } \\
\text { didn't (worry I would break it).' } \\
\text { 'Sometimes it forces you to do things according to } \\
\text { a fixed protocol in a fixed order.' }\end{array}$ \\
\hline Negative comments & 4 & 10 & $\begin{array}{l}\text { 'Don't really see how this is helpful to me at this } \\
\text { stage } \\
\text { Felt a little bit like it was going to trick you into } \\
\text { a dead end!' } \\
\text { 'The process felt a bit unrealistic as in practice } \\
\text { you often do things alongside each other rather } \\
\text { than in sequence.' }\end{array}$ \\
\hline
\end{tabular}

Table 3(ii)

Student responses to question. 'What did you learn from the quandary?'

\begin{tabular}{|l|l|l|l|}
\hline Category of response & No. & $\%$ & \multicolumn{1}{|c|}{ Example } \\
\hline $\begin{array}{l}\text { More detailed } \\
\text { knowledge than had } \\
\text { previously had }\end{array}$ & 4 & 7 & $\begin{array}{l}\text { 'Definitions of certain things plus names of } \\
\text { interventions I know about but didn't know the } \\
\text { technical name.' } \\
\text { 'Defined some terminology (i.e. shaping, } \\
\text { functional analysis)' }\end{array}$ \\
\hline $\begin{array}{l}\text { Broad knowledge } \\
\text { about the process }\end{array}$ & 39 & 65 & $\begin{array}{l}\text { 'More about the process of referral through to } \\
\text { closing a case.' } \\
\text { 'Felt it gave me the opportunity to learn about } \\
\text { specific aspects of referral from start to finish-was } \\
\text { really useful to be able to follow a process like } \\
\text { that without fearing real mistakes in reality. }\end{array}$ \\
\hline
\end{tabular}

18 Journal of Practice Teaching \& Learning 8(2) 2008, pp.7-24. DOI: 10.1921/81130. (C) wEb 
Online clinical quandaries and trainee clinical psychology knowledge

\begin{tabular}{|l|l|l|l|}
\hline $\begin{array}{l}\text { Basic knowledge for } \\
\text { those with no previous } \\
\text { knowledge }\end{array}$ & 6 & 10 & $\begin{array}{l}\text { 'Felt I got a handle on some of the basic tools } \\
\text { involved in LD.' } \\
\text { 'Never worked in LD so very informative, good } \\
\text { way to think about how to approach this type of } \\
\text { problem.' }\end{array}$ \\
\hline Specific knowledge & 9 & 15 & $\begin{array}{l}\text { 'Learnt about recording methods to document } \\
\text { challenging behaviour.' } \\
\text { 'To consider medical related problems.' }\end{array}$ \\
\hline $\begin{array}{l}\text { Nothing new/ } \\
\text { reinforcing previous } \\
\text { knowledge }\end{array}$ & 2 & 3 & $\begin{array}{l}\text { 'Nothing new I'm afraid. Straightforward issues.' } \\
\text { 'It helps to refresh your memory and what you } \\
\text { have learned.' }\end{array}$ \\
\hline $\begin{array}{l}\text { Praise as a learning } \\
\text { tool }\end{array}$ & 32 & 78 & $\begin{array}{l}\text { 'Great! A v. useful learning tool it seems } \\
\text { Very useful learning experience.' } \\
\text { 'It seems to be very in depth and set up for } \\
\text { extensive learning-excellent tool } \\
\text { Implementing prior knowledge.' }\end{array}$ \\
\hline
\end{tabular}

\section{Discussion}

The study aimed to assess the impact of an online challenging behaviour quandary on the knowledge of first year trainee clinical psychologists, as well as evaluating trainees' experiences of using the quandary. It was hypothesized that, if the quandary had been designed as an effective game informed learning activity, then it could result in a statistically significant increase in basic knowledge in relation to assessment and management of challenging behaviour in people with a learning disability, even before the trainees had received any other form of educational input.

The results indicated that trainee knowledge scores showed a significant increase in relation to dealing with the 'initial referral', 'recording' and 'overall total', with a medium effect size for all three comparisons. While scores were higher at follow-up in relation to the factors of 'functional analysis', 'intervention' and 'evaluation', this did not reflect a statistically significant increase. This may be because these three factors were comprised of fewer questions and, in the case of the 'evaluation' factor, this comprised of only one question. While the trainees had not yet received any clinical psychology training when they completed the baseline questionnaire, they would all have had some relevant clinical and or research experience prior to coming on the course (as this is an entry requirement). This means that most would be likely to have some basic understanding of the areas being assessed and taught by the challenging behaviour quandary, particularly as it was likely that a number of trainees had previous experience of working in

19 Journal of Practice Teaching \& Learning 8(2) 2008, pp.7-24. DOI: 10.1921/81130. @ w wb 
the learning disability field. It may be that this basic knowledge, combined with the lower maximum possible score led to a ceiling effect for these three factors, in that trainees already had quite good basic knowledge prior to using the quandary.

Overall, however, the results indicate that the use of the clinical quandary alone, in the context of the trainees having received no other form of postgraduate training, was sufficient to significantly increase their knowledge in relation to three of the main areas relating to the successful management of challenging behaviour, as well as significantly increasing their overall knowledge scores relating to this area.

\section{Trainee evaluations of the challenging behaviour clinical quandary}

Many authors note the importance of including user assessments in evaluations of game informed learning activities (de Freitas, 2006; Begg et al., 2007). The results indicated that, in general, the trainees found the quandary interesting, sufficiently challenging and stimulating to use and helpful as a study aid. The mean rating indicated that they felt they had sufficient control over the direction the quandary took and that they would be very likely to use the quandary again. Gee (2003) notes a successful game engages the learner and motivates them to enter the semiotic domain again and again. The trainee ratings suggest that they would be motivated to use the quandary again as a learning tool.

These results were backed up by the open-ended questions. The majority of trainees praised the quandary as a learning tool. In addition, the quandary seemed to succeed to some extent in meeting the needs of those who had widely differing levels of previous knowledge and experience (de Freitas and Oliver, 2006). All but one of the trainees who responded felt that they had learnt something, whether it was a reinforcement of or adding to previous learning or providing a broad knowledge base to those who were new to the area of learning disability. Over a third of the trainees, however, found having no or only limited experience of the learning disability specialty a challenge when it came to completing the quandary. In addition, nearly half found the options that the quandary offered challenging, as a number of options appeared equally reasonable. This is not necessarily a bad thing as providing surprising feedback and a level of challenge can serve to engage the learner and allow them to learn

20 Journal of Practice Teaching \& Learning 8(2) 2008, pp.7-24. DOI: 10.1921/81130. (๐ w\&b 
through experimentation and experience rather than through rote learning of facts (de Freitas, 2006; Gee, 2003; Malone, 1980; Newman, 2004).

There were, however, also some technical and practical challenges that the trainees faced. A small number had difficulty with navigating around the quandary and one trainee expressed frustration at feeling forced to progress through the quandary in a rather rigid way. This relates to another criticism of the activity: that its linear structure did not reflect the reality of clinical practice, where many processes happen simultaneously. It is difficult to capture the complexity of clinical practice in a simple, predominantly narrative based online activity and so the activity may be less flexible and interesting than is optimal for a successful game informed learning tool (de Freitas, 2006; Gee, 2003; Rouse, 2001). Overall, however, trainee feedback indicated that they found the quandary to be a useful learning tool that was sufficiently interesting, stimulating and challenging to result in their wishing to use it again.

\section{Methodological limitations}

The challenging behaviour quandary would normally have been provided in the wider context of lectures and workshops on the topic. For the purposes of the evaluation, however, it was presented as a stand-alone activity. This meant that the trainees were not learning as part of an 'affinity group' (Gee, 2003) and were unable to share ideas (de Freitas, 2006), construct group knowledge, critically appraise or generalise their learning experience (Salmon, 2002), making the quandary less likely to be effective as a learning tool (Begg et al., 2005; Mitchell \& Savill-Smith, 2005).

There were also some limitations with the assessment method used in the present study.

The fact that some sub-scores had fewer items than others may have resulted in a ceiling effect, by which any increases in knowledge or incidental learning could not be picked up (Smith, 1996). The assessment method also failed to allow for more complex or sophisticated answers to receive additional points. While this was sufficient for the purposes of examining basic knowledge in relation to challenging behaviour, it did not allow for more subtle changes in learning to be picked up.

21 Journal of Practice Teaching \& Learning 8(2) 2008, pp.7-24. DOI: 10.1921/81130. @ w\&bb 
Karen McKenzie, Clara O'Shea, Paula Megson, Hamish Macleod, \& Michael Begg

Implications for practice and areas for future research

The results of the present study indicated that, limitations not withstanding, that a simple game informed learning activity, presented in isolation, offered a means of improving trainee knowledge. Using the clinical quandary significantly increased trainee knowledge in all but three areas which were identified as central to the successful assessment and treatment of challenging behaviour. Further research could examine the effectiveness of clinical quandaries as learning activities in other areas of clinical psychology training as well as in the provision of training to other professions. It may also be that involving trainees directly in the development of their own clinical quandaries provides an even more effective learning tool.

\section{References}

British Psychological Society (2001). Division of Clinical Psychology: Core philosophy and purpose of the profession. Leicester: British Psychological Society

Ball, T., Bush, A. and Emerson, E. (2004) Psychological Interventions for Severely Challenging Behaviours Shown by People with Learning Disabilities: Clinical practice guidelines. Leicester: British Psychological Society

Begg, M. (2008) Leveraging game informed learning in higher education. Medical Teacher, 30, 2, 155-158

Begg, M., Dewhurst, D., and Macleod, H. (2005). Game informed learning: Applying computer game processes to higher education. Innovate, 1, 6

Begg, M., Ellaway, R., Dewhurst, D., and Macleod, H. (2006) Virtual patients: Considerations of narrative and gameplay. Paper presented at the Digital Game Based Learning: 4th International Symposium for Information Design, Stuttgart Media University

Begg, M., Ellaway, R., Dewhurst, D., and Macleod, H. (2007) Transforming professional healthcare narratives into structured game informed learning activities. Innovate, 3, 6

Biggs, J. (1999) Constructing Learning by Aligning Teaching: Constructive alignment. Teaching for quality learning. Buckingham: Society for Research in to Higher Education and Open University Press, 11-32

Carpenter, J. (2005) Evaluating Outcomes in Social Work Education. Dundee/ London : Scottish Institute for Excellence in Social Work Education

22 Journal of Practice Teaching \& Learning 8(2) 2008, pp.7-24. DOI: 10.1921/81130. @ wEb 
Online clinical quandaries and trainee clinical psychology knowledge

(SIESWE) and the Social Care Institute for Excellence (SCIE)

Cohen, J. (1992) A power primer. Psychological Bulletin, 112, 1, 155-159

Collins, H. and Evans, R. (2007) Rethinking Expertise. London: The University of Chicago Press

de Freitas, S. and Oliver, M. (2006) How can exploratory learning with games and simulations within the curriculum be most effectively evaluated? Computers and Education Special Issue on Gaming. 46, 249-264

de Freitas, S. (2006) Learning in Immersive Worlds: A review of game based Learning. Joint Information Systems Committee. Available at: http://www.jisc.ac.uk/media/documents/programmes/elearninginnovation/ gamingreport_v3.pdf Last accessed 24th April 2008

Emerson, E., Robertson, J., Gregory, N., Hatton, C., Kessissoglou, S., Hallam, A. and Hillery, J. (2000) Treatment and management of challenging behaviours in residential settings. Journal of Applied Research in Intellectual Disabilities, 13, 197-215

Facer, K., Joiner, R., Stanton, D., Reid, J., Hull, R. and Kirk, D. (2004) Savannah: Mobile gaming and learning? Journal of Computer-Assisted Learning, 20, 399-409

Francis, R. (2006) Towards a pedagogy for game-based learning. Paper presented at JISC Online conference: Innovating with e-Learning 2006. 30th March. Cheltenham. Cited in De Feritas, S. (2006) Learning in Immersive Worlds: A review of Game Based Learning: JISC e-learning Programme. http://www.jisc.ac.uk/uploaded_documents/Summary_report. pdf Accessed 29th January 2007

Gee, J. P. (2003) What Video Games have to Teach Us about Learning and Literacy. New York: Palgrave Macmillan

Gee, J. (2005) What would a state of the art instructional video game look like? Innovate 1, 6. http://www.innovateonline.info/index. php?view=articleandid=80 (accessed March 5, 2008)

Green, C.S. and Bavelier, D. (2003) Action video game modifies visual selective attention. Nature, 423, 6939, 534-537

Lave, J. and E. Wenger (1991) Situated learning: Legitimate peripheral participation. Cambridge: Cambridge University Press

Maharg, P. (2006) On the Edge: ICT and the transformation of professional legal learning. Last accessed 31st July 2008 at: http://webjcli.ncl.ac.uk/2006/ issue $3 / \mathrm{html}$

Malone, T.W. (1982) Heuristics for designing enjoyable user interfaces: Lessons from Computer Games. Proceedings of the 1982 conference on human factors in computing systems, Gaithersburg, Maryland: United States

23 Journal of Practice Teaching \& Learning 8(2) 2008, pp.7-24. DOI: 10.1921/81130. @ wE-b 
Malone, T.W. (1980) What makes things fun to learn? Heuristics for designing Instructional Computer games. Proceedings of the $3^{\text {rd }}$ ACM SIGSMALL symposium and the first SIGPC symposium on Small systems. Palo Alto, California, United States

McKenzie, K., Simpson, F., Matheson, E., Murray, G.C. and Paxton, D. (2000) Challenging experiences. Learning Disability Practice, 2, 3, 8-11

Mitchell, A. and Savill-Smith, C. (2005). The use of Computer and Video Games for Learning. A review of the literature. London. Learning and Skills Development Agency

Newman, J. (2004) What is a Videogame? Rules, puzzles and simulations. in videogames. London: Routledge

O'Neil, H. F., Wainess, R. and Baker, E.L. (2005). Classification of learning outcomes: Evidence from the computer games literature. Curriculum Journal, $16,4,455-474$

Rouse, R. (2001) Game Design: Theory and practice (2nd ed.): Wordware Game Developer's Library http://www.gamedev.net/reference/articles/article2184. asp Accessed on 29th January, 2007

Salmon, G. (2002). 'The five-stage framework and e-tivities,' in E-tivities: The key to active online learning. London: Kogan Page (pp. 10-36)

Sandford, R., Ulicsak, M., Facer, K. and Rudd, T. (2006) Teaching with Games: Using commercial off the-shelf computer games in formal education. Bristol. Futurelab

Shaffer, D.W. (2005). 'Epistemic Games', Innovate, 1, 6

Available at: http://innovateonline.info/index.php?view=articleandid=79andacti on=article Last accessed $7^{\text {th }}$ May 2008

Shaffer, D.W. (2004) Epistemic frames and islands of expertise: Learning from infusion experiences. Paper presented at the International Conference of the Learning Sciences, Santa Monica, CA, Cited in Gee J.P. (2005) What would a state of the art instructional video game look like? Innovate 1, 6 Http://www.innovateonline.info/print.php?id=80andview=html Accessed $29^{\text {th }}$ January 2007

Smith, M (1996) Competence and competency. The Encyclopedia of Informal Education. Available at: http://www.infed.org/biblio/b-comp.htm Last accessed 8th May 2008

24 Journal of Practice Teaching \& Learning 8(2) 2008, pp.7-24. DOI: 10.1921/81130. ( $w \& b$ 